Article - Smart Energy

\title{
Technical and economic viability of the installation of a hybrid solar-wind generation system in a Brazilian industry
}

\author{
Mauro Obladen de Lara Filho' \\ https://orcid.org/0000-0002-7306-4369 \\ Clodomiro Unsihuay-Vila ${ }^{1}$ \\ https://orcid.org/0000-0002-1639-7765 \\ Vilson Roiz Gonçalves Rebelo da Silva ${ }^{1}$ \\ https://orcid.org/0000-0002-2660-9717
}

${ }^{1}$ Federal University of Paraná, Electrical Engineering Department, Curitiba, Paraná, Brazil

Received: 2018.11.05; Accepted: 2019.07.26.

* Correspondence: mauroobladen4@gmail.com; Tel.: +55-41-996319861 (M.O); clodomiro.unsihuay.vila@gmail.com; Tel.: +55-41-984552746 (C.U); vilroiz@eletrica.ufpr.br; Tel.: +55-41-988834574 (V.R)

\section{HIGHLIGHTS}

- Combined solar and wind power microgrid.

- Case study in an existing industry.

- Several investment options considered

\begin{abstract}
The demand for electricity is growing worldwide. At the same time, the non-renewable natural resources that account for a large proportion of the global energy matrix are rapidly depleting, which will pose a major challenge in the near future. Therefore, micro-grid models that use renewable energy sources, such as solar and wind, are rapidly developing and are becoming economically viable alternatives. The objective of this study was to evaluate the economic viability of installing solar and wind power generation systems in the NOVVALIGHT electrical components factory located in Campo Largo, Paraná, Brazil. The most viable model was the combination of solar and wind energy, which would generate approximately $260 \mathrm{MWh}$ of energy per year. Using financing provided by the Brazilian Bank for Economic and Social Development (BNDES), this proposal has an eight-year payback period, net present value of BRL 149,097.42, and internal rate of return of $18 \%$, demonstrating its economic viability.
\end{abstract}

Keywords: distributed generation, solar energy, wind energy. 


\section{INTRODUCTION}

Electricity is one of the most important resources for all countries. Global electricity consumption in 2017 grew by 2.6\% from the level 2016 [1]. Although the consumption in some developed countries has declined due to the stabilization of the population's demand combined with an increase in the energy efficiency of their loads, electricity consumption in developing countries, such as China, Brazil, and India, has significantly grown. In Brazil, according to a recent update to the Ten-Year Energy Expansion Plan, the average load expansion rate will reach approximately $3.8 \%$ per year, indicating an average growth of $2900 \mathrm{MWmed} / \mathrm{year}$ up to 2024.

In addition to the growing demand for energy, another challenge for the sector is the composition of the energy matrix. Most countries use large quantities of non-renewable fossil fuels to generate electricity. Even Brazil, where there is vast and well-exploited hydroelectric potential, generates over $15 \%$ of its energy from non-renewable fuels, with natural gas, petroleum products, coal, and nuclear sources accounting for $9.8 \%, 2.1 \%, 2.9 \%$, and $2.7 \%$ of this [2].

Thus, the growing demand and depletion of natural resources are major challenges that the energy sector currently faces and will continue to face in the future.

A possible solution to this challenge is the implementation of microgrids, where energy is produced through a variety of distributed renewable and theoretically inexhaustible sources, such as solar, wind, and biomass, diminishing the need to expand centralized generation systems and our dependence on fossil and non-renewable fuels.

Since 2015, energy tariffs have increased well above inflation in Brazil, prompting many consumers to generate their own energy to seek financial savings. According to the Brazilian Electrical Energy Agency (ANEEL), in 2015, there were 1,823 distributed generation connections in the grid, with a total installed capacity of $17 \mathrm{MW}$. In July 2018, the number grew by over 20 times to 33.3 thousand generators with an installed capacity of $403 \mathrm{MW}$.

Furthermore, the price of equipment for distributed generation is decreasing with the development of technology. For example, the costs of solar panels and frequency inverters have decreased. This trend is likely to improve the viability of microgrid systems over time. Therefore, companies should study the economic viability of these systems to reduce energy costs and achieve independence from the fluctuating energy tariffs.

The overall objectives of this study are to design a hybrid distributed generation system that includes photovoltaic and wind generation to supply the demand of NOVVALIGHT, a factory in Campo Largo, Curitiba, that produces lighting equipment for various applications, including industrial and public lighting, and assess the economic viability of the project by calculating the payback period, net present value (NPV), and internal rate of return (IRR).

\section{MATERIAL AND METHODS}

\section{Photovoltaic System}

To properly design a photovoltaic system, it is necessary to obtain reliable solar irradiation data for the region intended for the installation. There are several databases available for this, but they often contain different data. Two of the most reliable databases in Brazil are the Radiasol software, developed by the Solar Energy Lab (LABSOL) of the Federal University of Rio Grande do Sul (UFRGS), and SunData, developed by the Reference Center for Solar and Wind Energy (CRESESB).

Initially, we intended to use Radiasol as it contains daily data and can also support slope and azimuthal deviation data, however, the software does not contain data regarding the municipality of Campo Largo. Therefore, data for Curitiba and Campo Largo in the horizontal plane without azimuthal deviation obtained by SunData were used to determine the proportionality between the data for the two cities, as shown in equation 1.

$$
I R_{\text {C.Largo }}=I R_{\text {curitiba }} \text { inclined } *\left(\frac{I R_{\text {campolargohorizontal }}}{I R_{\text {curitibahorizontal }}}\right)
$$


Another important factor is the load profile of the site, which should be considered to ensure that the generation system is designed to prevent an excess or lack of generated energy at any point in the site. Therefore, energy bills obtained from the local power distribution company, COCEL, over a period of 12 months were analyzed.

Once the necessary amount of power generation was determined, the photovoltaic panels to be used were selected considering the relationship between the investment to be fulfilled and the maximum power to be generated (BRL/Wp).

It was also necessary to determine the inclination angles of the panels. To maximize generation, it is recommended that panels are orientated towards the equator. Villalba and Gazoli (2012) recommend that panels should be installed according to Table 1 [4].

Table 1. Recommended angles for solar panels

\begin{tabular}{cc}
\hline Latitude & $\begin{array}{c}\text { Recommended } \\
\text { Angle }(\alpha)\end{array}$ \\
\hline 0 to $10^{\circ}$ & $\alpha=10^{\circ}$ \\
11 to $20^{\circ}$ & $\alpha=$ latitude \\
21 to $30^{\circ}$ & $\alpha=$ latitude $+5^{\circ}$ \\
31 to $40^{\circ}$ & $\alpha=$ latitude $+10^{\circ}$ \\
Greater than $40^{\circ}$ & $\alpha=$ latitude $+15^{\circ}$ \\
\hline
\end{tabular}

As Campo Largo lies at a latitude of $25^{\circ}$, the ideal angle for installing the modules is $30^{\circ}$. However, to ensure that the panels can be installed at this angle, it would be necessary to invest heavily in the support structures of the panels. Therefore, we decided to use the existing roof structure, which has a slope of approximately $10^{\circ}$ and azimuthal deviation of $34^{\circ}$.

With these angles, and by using equation 1, average power generation of 4.3 $\mathrm{kWh} / \mathrm{m}^{2 *}$ day was achieved.

According to COCEL, the average monthly consumption of the company was 22,322 $\mathrm{kWh}$. With an average of 30 days per month, the daily average consumption was $744 \mathrm{kWh}$.

Eight different panel models were compared: Canadian Solar CS6K-270P, CS6P-265P, C6SP-260P and C6SP-255P, Yingli Solar YL275D-30b and YL245P, Komaes 250W, and Seraphine SRP-265-6PB. After obtaining the prices of the eight models, the best option for meeting the price per peak power criterion was Canadian Solar C6SP-270P, with an estimated cost of BRL 599,00 and peak power of $270 \mathrm{~W}$, resulting in a relationship of BRL 2.22/Wp, according to Table 4.

A Symo 12.5-3M inverter from Fronius was used, which has a capacity of up to $12500 \mathrm{~W}$ input and costs BRL 18,390.00, resulting in a cost of BRL 1520.00/kW.

Equation 2 can be used to calculate the amount of photovoltaic power that would be installed.

$$
P f v=\frac{E}{I R * P R}
$$

where $E$ is the energy that would be generated daily, IR is the daily solar irradiation, and PR is the performance ratio of the system, estimated to be $80 \%$.

Therefore, using the data presented, the amount of photovoltaic power to be installed is $216.29 \mathrm{kWp}$.

As the selected panel has a peak power of $270 \mathrm{~W}, 812$ panels are required to supply the company's energy demand.

However, the area required for installing 812 panels on the roofs of NOVVALIGHT was larger than that available. Thus, the arrangement was limited to 600 photovoltaic panels, resulting in an installed capacity of $162 \mathrm{kWp}$. 
Frequency inverters have an input voltage range that allows the maximum power utilization of the associated panels. The range of the selected inverter is 200 to $800 \mathrm{~V}$. From the data supplied by the panel manufacturer, the voltage supplied by each panel is $30.8 \mathrm{~V}$. Therefore, it is necessary to place panels in series to ensure that the total voltage generated is within the optimum range of the frequency inverters.

A series of seven panels can meet the minimum voltage of $200 \mathrm{~V}$, while the voltage generated by a series of 26 panels exceeds the maximum. Therefore, the arrangements can contain seven to twenty-five panels.

As the inverter has six inputs and a maximum input current of $40.5 \mathrm{~A}$, the arrangements should be designed so that this current is not exceeded. As one panel provides a maximum current of $9.32 \mathrm{~A}$, arrangements can be connected to four of the six inputs, totaling a current of $37.28 \mathrm{~A}$. Therefore, we decided to use three parallel strings, each with 20 panels in series, resulting in a maximum input voltage and current of $616 \mathrm{~V}$ and $27.96 \mathrm{~A}$, respectively, which are within the technical limitations of the inverter.

Finally, the conductors, circuit breakers, and other components of the circuit were selected based on Brazilian technical standard NBR 5410.

Using local solar irradiance data and the installed solar system, the expected monthly energy generation can be calculated and compared with the energy consumption of the company, as shown in Figure 1.

\section{Generation x Consumption (monthly)}

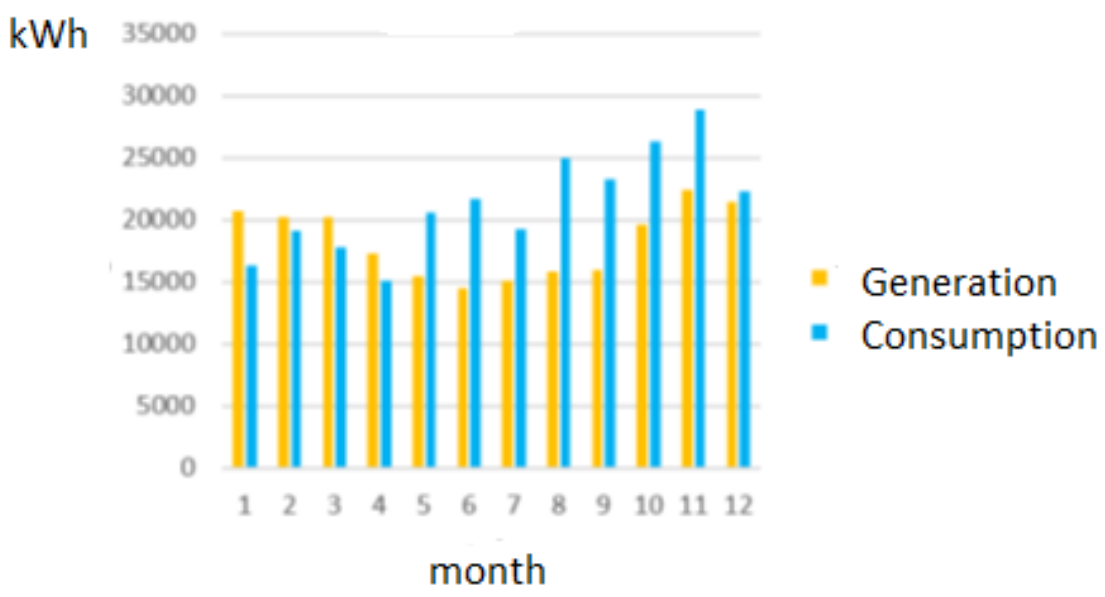

Figure 1. Balance between energy generation and consumption

The photovoltaic system can only fully meet the energy demand of the company during months with greater irradiation and lower consumption, i.e., January, February, March, and April. Therefore, it is necessary to complement the photovoltaic generation system with wind power so that the system can generate all the necessary energy.

\section{Wind system}

As with the photovoltaic system, the design of a wind system begins with the analysis of the availability of the energy resource. In the case of wind energy, it is necessary to determine the wind speeds of the desired region.

In addition to SunData, CRESESB also has a wind energy database. Another important database is BDMEP, developed by the Brazilian National Institute of Meteorology (INMET).

It was also necessary to cross-reference the wind data, as BDMEP holds no data for Campo Largo; it only contains data for Curitiba. However, BDMEP data are interesting as they are presented on an hourly basis. Thus, the procedure followed for the photovoltaic 
system was followed again to establish the ratio of proportionality between the values for Curitiba and Campo Largo from CRESESB and then apply it to the Curitiba data from BDMEP to obtain data specific for Campo Largo.

From the obtained data, the Weibull distribution was applied to generate a graph that relates the different wind speeds to their probability of occurrence, as shown in Figure 2.

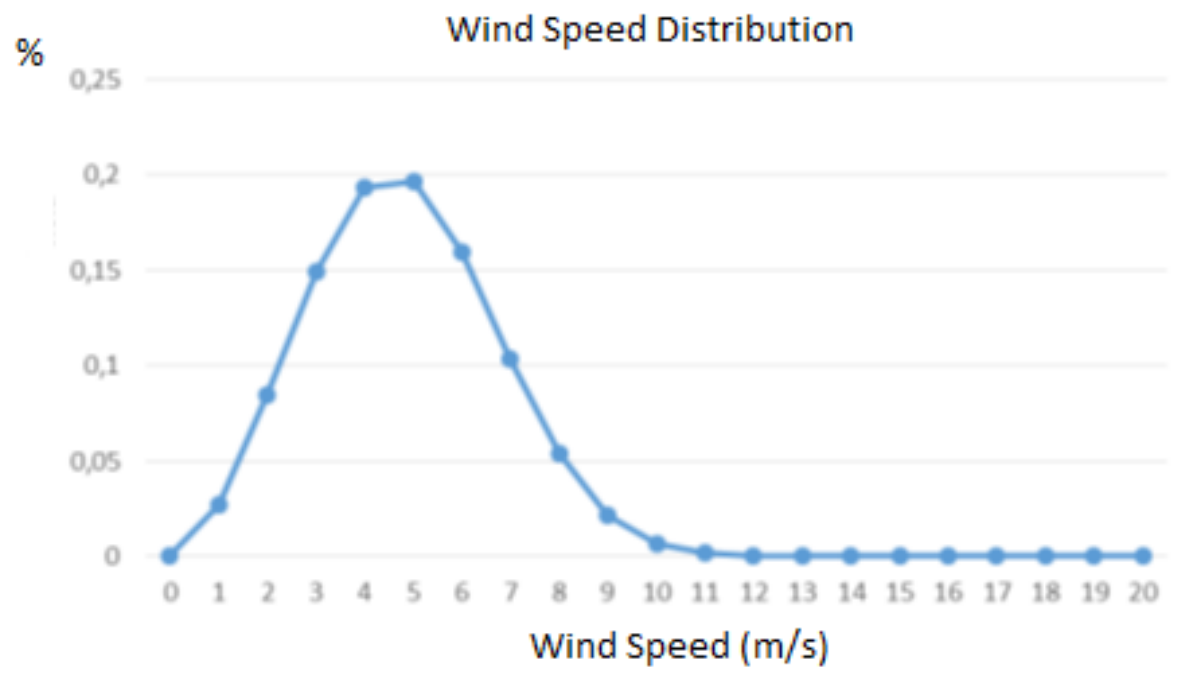

Figure 2. Wind speed probability distribution

It is then necessary to select the wind turbines to be used in the project. For this, parameters, such as the starting speed in accordance with the intensity of the winds in the region, the nominal and maximum speeds, and the maximum operating power, should be considered.

The power curves of the TREBA-0160, TREBA-0210, TREBA-0201, Southwest Windpower Skystream Land 3.7, WRS-WES50, WRS-WES 80, and WRS-WES100 models were compared, and TREBA-0210 was selected for the project as it generated the most power at the most probable wind speeds according to the Weibull distribution.

Another factor to be considered is the altitude. The database considers a tower height of $50 \mathrm{~m}$, but the tower of the selected wind turbine is only $24 \mathrm{~m}$ tall. Equation 3 can be used to correct these the values.

$$
V=V_{0} *\left(\frac{H}{H_{0}}\right)^{a}
$$

where $V$ is the wind speed at height $H, V_{0}$ is the wind speed at a height $H_{0}$, and $a$ is the Hellman coefficient. A Hellman coefficient of 0.2 [7] can be adopted for an open area with hedges.

The corrected Weibull distribution was then calculated, as shown in Figure 3. 


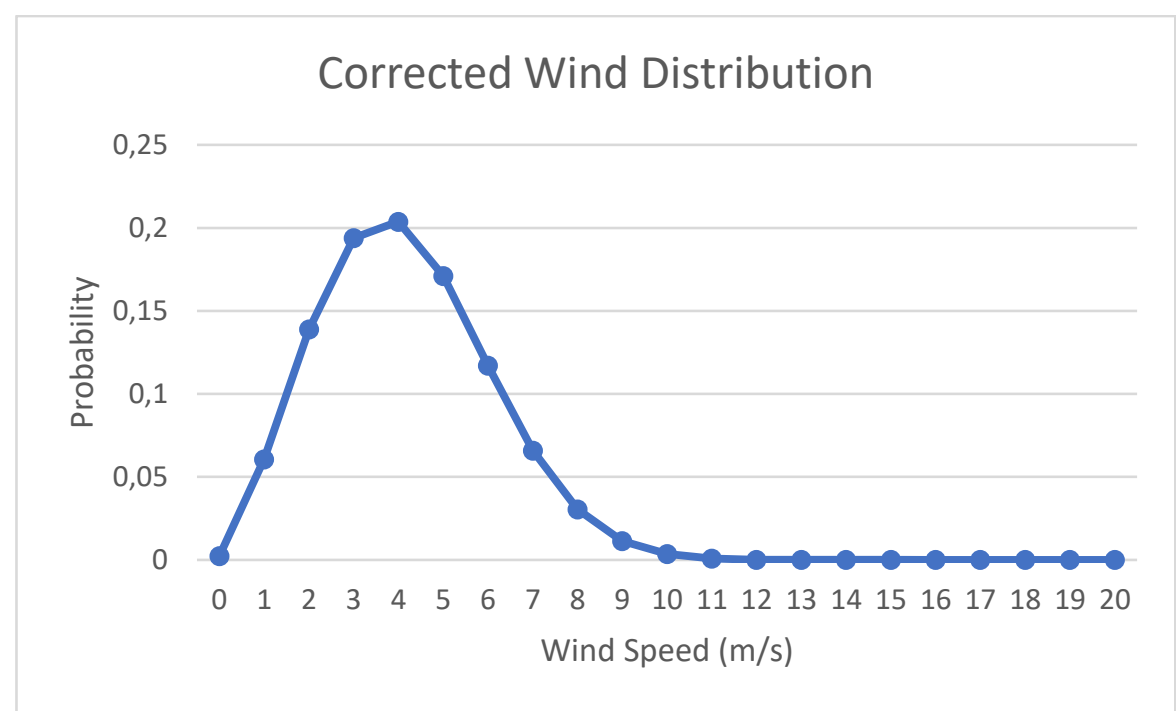

Figure 3. Corrected wind speed distribution

According to data in the literature, wind turbines must have a lateral spacing of 1.5 to 3 rotor diameters and frontal spacing of 8 to 10 rotor diameters. The diameter of the selected aerogenerator is $13.8 \mathrm{~m}$. Therefore, the adopted lateral and frontal spacings were 21 and $115 \mathrm{~m}$, respectively. Thus, twelve wind generators can be installed in the area of the factory in two rows with six towers side by side.

The energy generated by this arrangement can be calculated using equation 4 .

$$
E=P_{g} * W s * t
$$

where $\mathrm{Pg}$ is the power of the wind turbine, Ws is the wind speed, and $\mathrm{t}$ is the period for which this speed occurs during the year.

The amount of energy that could be generated annually is presented in Figure 4.

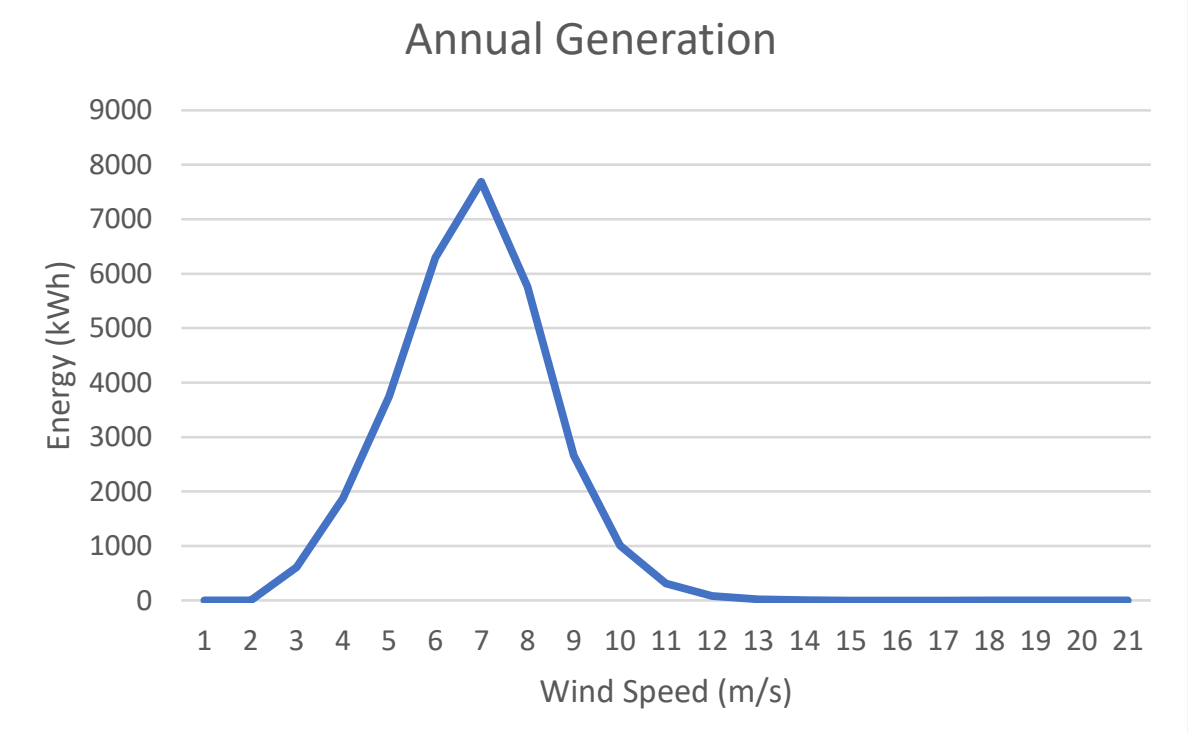

Figure 4. Expected energy generation from wind

Each wind turbine can generate $30.1 \mathrm{MWh} /$ year. The average annual energy consumption of the company is $260 \mathrm{MWh}$. Therefore, the installation of eight wind turbines can generate $240 \mathrm{MWh} /$ year.

The conductors and circuit breakers were again selected according to the Brazilian technical standards. 

Figure 5.

Finally, the expected energy generation and consumption were compared, as shown in

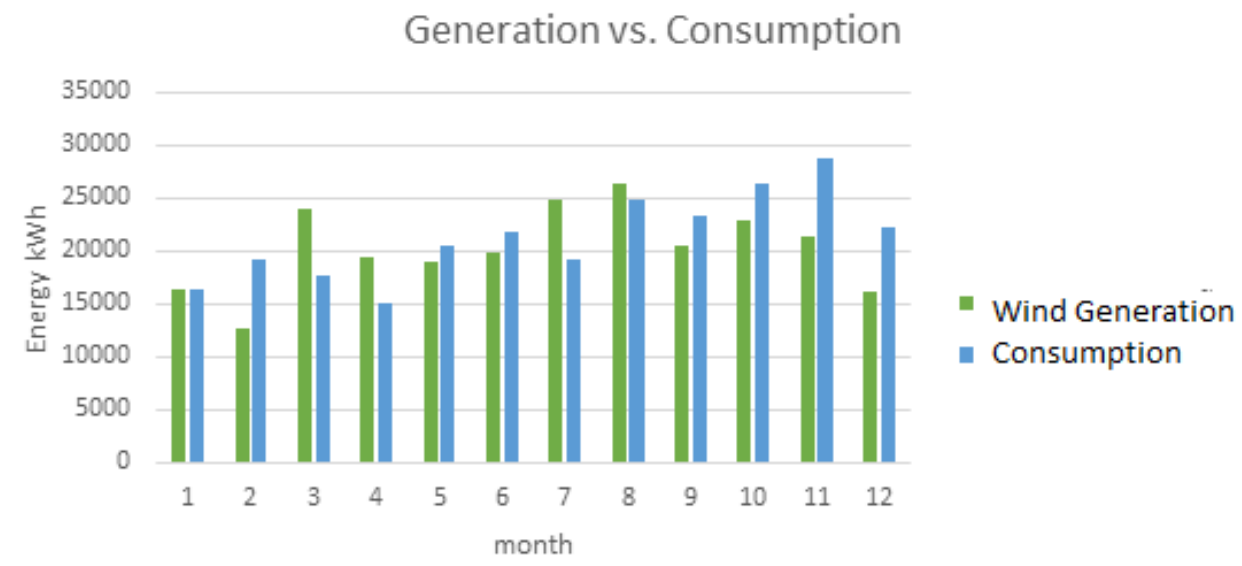

Figure 5. Balance between energy generation by wind and consumption

\section{RESULTS}

The installation costs of the photovoltaic system were estimated to be BRL $754,151.73$.

Two different investment situations were considered: the utilization of the company's capital, resulting in a NPV of BRL $122,468.63$ and an IRR of $16 \%$, with a seven-year payback period, and financing by BNDES, which would finance up to $80 \%$ of the investment value with an annual interest rate of $2.1 \%$ and payment due in 11 years. This scenario had a nine-year payback period, with a NPV of BRL 140,839.81 and IRR of $19 \%$.

For the wind system, costs were not calculated directly and only estimated as there were several problems due to the non-disclosure and confidentiality of equipment prices, particularly wind turbines. Thus, to evaluate the cost of the project, an average was taken from the values suggested by two different references. The first reference suggests a cost of BRL 4.2 million per installed MW. However, Bergey Windpower suggests a cost between $\$ 48,000$ and 65,000 per $10-\mathrm{kW}$ turbine to be installed. Therefore, by averaging these values, an investment of BRL 1,331,944.00 was estimated. [5] [6]

The same two scenarios considered for the photovoltaic system were analyzed. The utilization of the company resources achieved an IRR of $15 \%$, NPV of BRL 45,891.37, and payback period of eight years. With the financing option, the payback period increased to 10 years, and the NPV and IRR increased to BRL 120,785.08 and 17\%, respectively.

As mentioned previously, considering the low wind potential of the region and the limitations of area for supplying the energy used by the company by solar power alone, we simulated a hybrid generation system with wind power complementing photovoltaic generation. Thus, several IRR and NPV were simulated considering different proportions of generation by wind and solar, as shown in Figure 6 . 


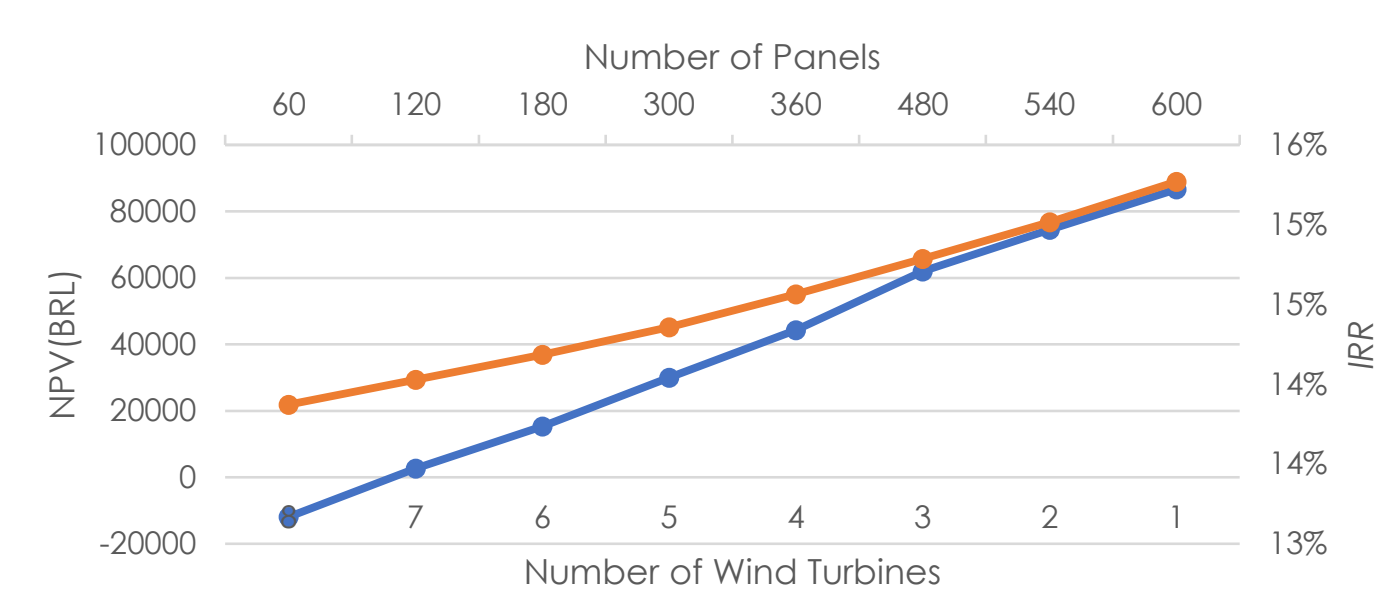

Figure 6.: Hybrid solar-wind scenario. The orange line is the IRR and the blue line is the NPV

Thus, a distribution with solar generation providing $89 \%$ of the installed capacity, corresponding to the arrangement of 600 panels, and wind generation providing $11 \%$ was selected as solar energy has greater economic viability in the region.

This option achieved a NPV of BRL 75,453.61, IRR of $15 \%$, and eight-year payback period if the company's resources are used, and an eight-year payback period, NPV of BRL $149,097.42$, and IRR of $18 \%$ if the project is financed by with BNDES.

\section{DISCUSSION}

All projects achieved satisfactory levels of economic viability, with a minimum attraction rate of $12 \%$ and positive NPV. However, the study was limited by the difficulties faced in obtaining the prices of wind system components due to the confidentiality of the data. However, the conclusions related to the advantages of solar energy in relation to wind power are valid, as the wind potential of the region is quite low, with typical speeds of 4 to $5 \mathrm{~m} / \mathrm{s}$. In the future, the possibility of using energy storage systems to compensate for the uncertainties of solar power should be considered. Although the generation system was designed to supply the total monthly energy consumption of the factory, solar panels do not generate a lot of energy during peak hours. Thus, the credits accumulated during the day do not have the same monetary value as the energy consumed during peak hours. By implementing an energy storage system coupled with an energy management system, it would be possible to store energy for discharge during the peak period, avoiding the consumption of more expensive energy from the grid.

Distributed power generation is currently a viable alternative for companies to gain independence from power distribution companies and reduce their electricity costs. The trend is currently positive, because, with the advancement of technology, the panels and wind turbines will be able to generate more energy at a lower cost.

\section{REFERENCES}

1. Global Energy Statistical Yearbook 2018 [Internet]. Grenoble: ENERDATA. c2009-2019. available from: https://yearbook.enerdata.net/electricity/electricity-domestic-consumption-data.html

2. Statistical Yearbook of Electricity 2017 [Internet]. Brasília: The Energy Research Company. c2017. Available from:

http://www.epe.gov.br/sites-pt/publicacoes-dados-abertos/publicacoes/PublicacoesArquivos/publica cao-160/topico-168/Anuario2017vf.pdf

3. Electric Energy Research Center (CEPEL). Engineering Manual for Photovoltaic Systems. Rio de Janeiro, 2014. 
4. Gazolli JR, Villalva MG, Guerra J; [Photovoltaic solar energy - grid-connected systems: connection requirements and protections] Energia solar fotovoltaica - sistemas conectados à rede elétrica: requisitos para a conexão e proteções. O Setor Elétrico; 2012; 83. Portuguese.

5. bergey.com [Internet]. Norman (OK): Bergey Wind Power. Available from http://bergey.com/wind-school/residential-wind-energy-systems

6. De Souza GHS, Lima NC, Queiroz JV, Penedo AST, Coelho JAPM, Costa, ACS; Marketing approach of Brazilian wind energy sector, J. Technol. Manag. Innov. 2013 Jul 30; 8(4) 2013: 46-58.

7. Rohatgi JS, Nelson V. Wind characteristics: an analysis for the generation of wind power. Canyon (TX): Alternative Energy Institute, West Texas A\&M University; 1994.

(c) 2018 by the authors. Submitted for possible open access publication under the terms and conditions of the Creative Commons Attribution (CC BY NC) license (http://creativecommons.org/licenses/by-nc/4.0/). 